\title{
Family history in developmental dysplasia of the hip: should we follow-up?
}

\author{
Sonay Aydın, Erdem Fatihoğlu ${ }^{2}$ \\ ${ }^{1}$ Department of Radiology, University of Health Sciences, Dr. Sami Ulus Training and Research Hospital, Ankara, Turkey \\ ${ }^{2}$ Department of Radiology, Erzincan University School of Medicine, Erzincan, Turkey
}

DOI: $10.18621 /$ eurj.442402

\begin{abstract}
Objectives: Developmental dysplasia of the hip (DDH) is an important problem. Ultrasonography (US) is a proper method before 6 months of age. For older children, plain radiographs can be useful. Six risk factors are emphasized: breech presentation, female sex, a positive family history, being first-born, left hip affected, and mode of delivery. In some centers, clinicians prefer to perform a control US examination or pelvic radiographs after 6 months of age for the children having a positive family history. We aimed to evaluate the necessity of control US/direct radiography examinations.

Methods: A total of 205 children with a positive family history for DDH are included. US examinations are performed according to Graf's method. We have evaluated direct radiographs by using Hilgenreiner, Perkin, and Shenton lines, acetabular angle.

Results: Initial US examinations are performed at a median age of 8.3 weeks. Seventy-four patients $(36 \%)$ had a repeat ultrasound scan at a median age of 7 months; none of them demonstrated abnormal findings. One hundred and thirty-one patients (63.9\%) had control radiographs at a median age of 8.2 months. Shenton line is considered as normal, and the upper femoral epiphysis is located in inferomedial quadrant according to Hilgenreiner and Perkin lines.

Conclusions: A positive family history for DDH may be a less important reason for performing control US or radiographic examination. Patients with a normal screening US result and having risk factors can be discharged from follow up safely, so that unnecessary examinations and family anxiety will be reduced.
\end{abstract}

Keywords: Developmental dysplasia of the hip, Graf method, ultrasound, family history, follow-up

Received: July 10, 2018; Accepted: November 11, 2018; Published Online: July 22, 2019

Dosing evelopmental dysplasia of the hip (DDH) is a common and important problem, with a prevalence of 0.1 to $2 / 1000$ children. Delayed diagnosis and treatment can cause premature degenerative joint disorder, functional impairments, chronic pain, permanent disability, etc. Screening with only physical examination provides a correct diagnosis approximately $50 \%$ of cases with dislocated hip by the first year of life. Screening with ultrasonography (US) reduces the rates of open reductions and complications by $46 \%$ [1-4].

Graf's US investigation technique is used widely as a screening tool for DDH diagnosis [5]. Screening of all children with US is not widely accepted. It is recommended to perform US to the cases that have a physical examination finding $[6,7]$. US is a proper Address for correspondence: Sonay Aydın, MD, University of Health Sciences, Dr. Sami Ulus Training and Research Hospital, Department of Radiology, Ankara, Turkey E-mail: sonaydin89@hotmail.com,Fax:+903125953898 
method for the children before 6 months of age, because at this time femoral head is largely cartilaginous. For the children older than this, plain anteroposterior pelvic radiographs can be useful $[8,9]$.

In the literature six common risk factors are widely emphasized for DDH: breech presentation, female sex, family history, first-born, left hip affected, and mode of delivery [10]. Before the usage of US screening, studies reported that the incidence of late DDH is higher in children with a positive family history [11]. In some centers, especially in the ones who are not specifically interested in DDH cases, clinicians prefer to perform a control US examination or pelvic radiographs after 6 months of age for the children having a positive family history for DDH [12].

In the current study, we aimed to evaluate the necessity of control US/direct radiography examinations for the children with a positive family history of DDH. So that, unnecessary examinations and exposure to ionizing radiation might be reduced.

\section{METHODS}

Approval for this prospective study was granted by the institutional ethics review board. The study was conducted retrospectively, in two different centers. We have retrospectively evaluated 683 children who were screened for DDH. We have excluded the ones with a US examination result other than Graf type 1 hip. We have included the ones with a positive family history and a follow up examination. US results were not normal (Graf type 1) in 81 cases, family history is negative in 77 cases, 320 cases are not reexamined. Finally, 205 children are included into the study.

We have evaluated screening US results, and control US/direct radiography results. US examinations are performed according to Graf's method (Figure 1). We have evaluated direct radiographs by using Hilgenreiner, Perkin, and Shenton lines, acetabular angle (Figure 2). Patient's ages and sex, accompanying risk factors, other than family history are also noted.

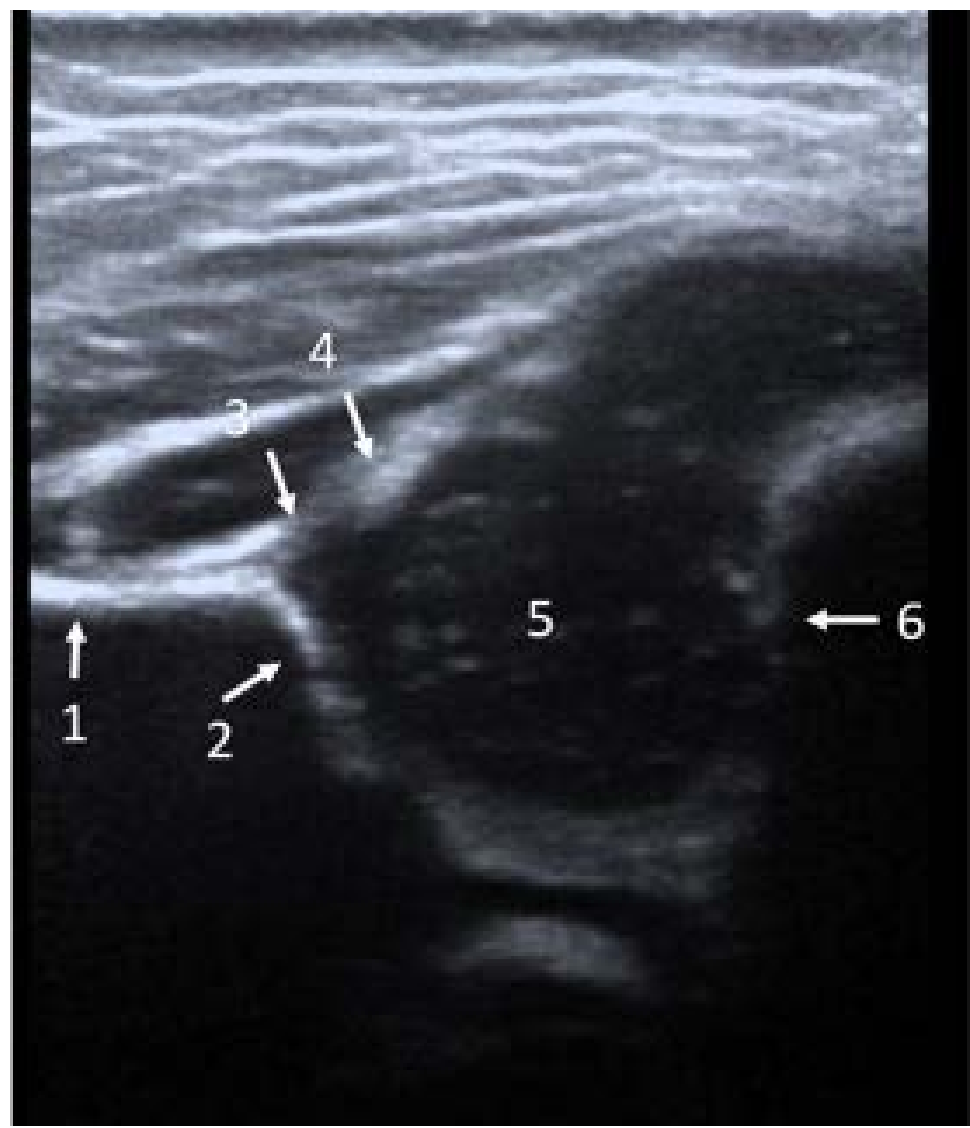

Figure 1. Coronal US view of a normal hip. 1, iliac bone; 2, lower limb of the ilium and bony acetabular roof; 3, cartilaginous acetabular roof; 4, acetabular labrum; 5, cartilaginous part of the femoral head (hyaline cartilage); 6 , chondro-osseous junction between the bony part and the cartilaginous part of the femoral neck. 


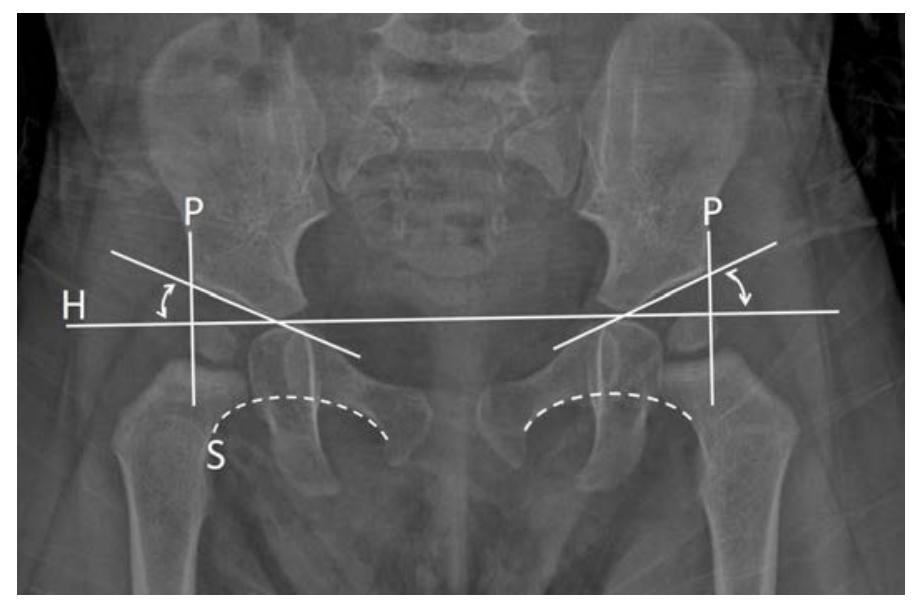

Figure 2. H: Hilgenreiner line, P: Perkin line, S: Shenton line, arrow: acetabular angle.

\section{Statistical Analysis}

All study information was recorded on patient data sheets, then entered into an Excel (2007, Microsoft Corp., Redmond, WA) spreadsheet for analysis. All data entries were double-checked by one of the investigators. Data were analyzed using Statistical Package for the Social Sciences (SPSS) for Windows 20 (IBM SPSS Inc., Chicago, IL). Normal distribution of the data was evaluated with the KolmogorovSmirnov test. Numeric variables that had a normal distribution were shown as mean \pm standard deviation. The variables that did not have a normal distribution were shown as median (interquartile range). For comparison of the numeric variables between the two groups student's T test and Mann-Whitney U test were used.

Table 1. Patients having two control radiographs

\begin{tabular}{lcc}
\hline Patient no & $\begin{array}{c}\mathbf{1}^{\text {st }} \text { acetabular } \\
\text { angle }\end{array}$ & $\begin{array}{c}\mathbf{2}^{\text {nd }} \text { acetabular } \\
\text { angle }\end{array}$ \\
\hline 1 & 26.5 & 21.8 \\
2 & 27.3 & 21.8 \\
3 & 26.7 & 20 \\
4 & 27.1 & 21 \\
5 & 26.8 & 20.8 \\
6 & 27.2 & 21.3 \\
7 & 27.1 & 21.7 \\
\hline
\end{tabular}

\section{RESULTS}

Mean age of the population is 10 months \pm 3 weeks. Population consists of $141(68.8 \%)$ girls and $64(31.2 \%)$ boys. The initial US examinations are performed at a median age of 8.3 weeks (range 6.3-12 weeks). 74 patients $(36 \%)$ have a repeat ultrasound scan at a median age of 7 months (range 6-12 months); none of them demonstrate abnormal US or physical examination findings, and accepted as normal.

One hundred and thirty-one patients (63.9\%) have control radiographs at a median age of 8.2 months (range 6-21.2 months). For all of the patients, Shenton line is considered as normal, and the upper femoral epiphysis is located in inferomedial quadrant according to Hilgenreiner and Perkin lines.

Mean acetabular angle is $24.3 \pm 0.7$. Seven

Table 2. Patients having multiple risk factors

\begin{tabular}{lcc}
\hline Patient no & Risk factors & Acetabular angle \\
\hline 1 & BP, F & 25 \\
2 & BP, F & 26 \\
3 & BP, F, DB & 27,3 \\
4 & F, BP & 25,3 \\
5 & BP, F, DB & 27,1 \\
\hline
\end{tabular}

$\mathrm{BP}=$ Breech presentation, $\mathrm{F}=$ Female, $\mathrm{DB}=$ Difficult birth

patients $(3.4 \%)$ have multiple direct radiography examination ( 2 direct radiographs). We have used the initial examination to calculate mean acetabular angle. Amongst these 7 patients, 4 have multiple risk factors for DDH. Initial acetabular angles of these 7 patients are all higher than 26.4, however their final acetabular angles are within normal limits, lower than 22 (Table $1)$.

5 patients have multiple risk factors (more than two) (Table 2). Amongst them, only 4 have multiple direct radiography examination (2 direct radiographs). Mean acetabular angle of these 5 patients is slightly higher than whole population, but it is not statistically significant $(26.2 \pm 0.1$ vs. $24.3 \pm 0.7, p>0.01)$ (Figure $3)$. 


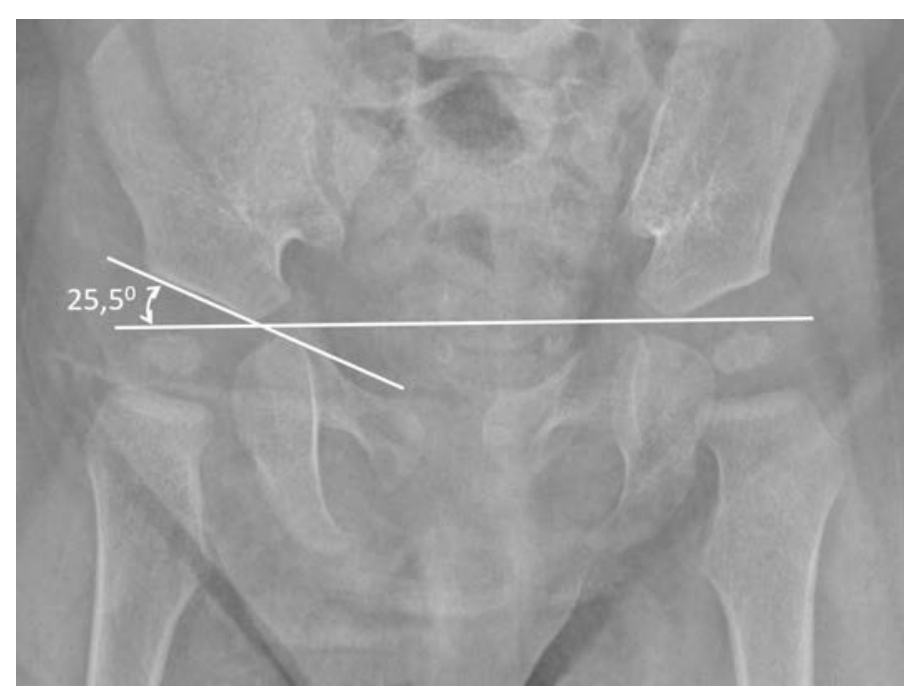

Figure 3. A patient with multiple risk factors. Acetabular angke is measured as 25.5 degrees.

\section{DISCUSSION}

DDH is still a common and important problem. An effective treatment, can prevent permanent disability [13]. The clinical evaluation for DDH is attributed to pediatrics professor Marino Ortolani. However, physical examination is not always enough to diagnose dysplastic, unstable or even dislocated hips. US, which were popularized by Graf in the 1980s, have been widely used to define and detect DDH [3, 14].

A positive family history is thought to be a strong risk factor for $\mathrm{DDH}$, as it is stated in the literature that an abnormal US result is found three times more in children with a positive family history for DDH [15]. When the children is examined with only physical examination, it is found that late dysplasia occurs in $18 \%$ of children [11]. This finding creates a clinical habit to perform a radiographic examination between 6-12 months.

Using both US examination and pelvic radiograph is still a method for some clinics. According to data obtained from British Society for Children's Orthopedic Surgery, 35 \%of surgeons said that they request a control radiograph from the patients with a normal ultrasound scan [16]. Price et al. found that an abnormal Radiograph is found only $0.5 \%$ of 11,000 patients with a normal initial US examination. They stated that a control radiograph is not necessary for patients with a normal US scan [17]. Specifically, some studies investigated the children with a positive family history for DDH to define the necessity of control radiographic examinations. It is stated that residual dysplasia in children with a family history of $\mathrm{DDH}$ and a normal hip ultrasound is not found significantly $[16,18]$. Our results are consistent with the literature, we have not detected any cases of late DDH, with a normal US result and positive family history.

The acetabular angle measured by using Hilgenreiner line is generally less than $28^{\circ}$ at birth. The angle will become smaller by age, and should measure less than $22^{\circ}$ at and beyond 1 year of age [19]. All of the children, who were classified as normal at initial US examination, have acetabular angles within normal limits. All of the patients who have more than one control direct radiographs have higher acetabular angles in comparison with the population. It is showing that a relatively higher acetabular angle, even within normal limits, might cause an unnecessary control radiographic examination. In the literature, it is stated that relatively high acetabular indexes come to normal limits in control examinations [12], even in children with risk factors. Our results are consistent with the literature; we cannot detect any late DDH cases in children with a relatively high acetabular angle.

In the literature there is not a similar study examining the possible correlations between presence of the risk factors and acetabular angle values. According to our results, children with multiple risk factors had slightly higher acetabular angles, but this is not a statistically significant difference. This might be the result of our small population. Further studies with larger populations can enlighten a possible correlation.

\section{Limitations}

The study has some limitations. First, the retrospective nature of the study is a limitation. Second, we do not have enough cases with multiple risk factors. Control examinations are not the same for all patients (US for some cases, direct radiograph for others). 


\section{CONCLUSION}

To conclude, having a positive family history for $\mathrm{DDH}$ is not a reason for performing control US or radiographic examination. Patients with normal screening US result and having risk factors can be discharged from follow up safely, so that unnecessary examinations and family anxiety will be reduced. If following up is still considered as necessary, US examinations can be performed instead of direct radiographs, as for avoiding ionizing radiation exposure.

\section{Conflict of interest}

The authors disclosed no conflict of interest during the preparation or publication of this manuscript.

\section{Financing}

The authors disclosed that they did not receive any grant during conduction or writing of this study.

\section{REFERENCES}

[1] Kyung BS, Lee SH, Jeong WK, Park SY. Disparity between clinical and ultrasound examinations in neonatal hip screening. Clin Orthop Surg 2016;8:203-9.

[2] Teixeira SR, Dalto VF, Maranho DA, Zoghbi-Neto OS, Volpon JB, Nogueira-Barbosa MH. Comparison between Graf method and pubo-femoral distance in neutral and flexion positions to diagnose developmental dysplasia of the hip. Eur J Radiol 2015;84:301-6.

[3] Thallinger C, Pospischill R, Ganger R, Radler C, Krall C, Grill F. Long-term results of a nationwide general ultrasound screening system for developmental disorders of the hip: the Austrian hip screening program. J Child Orthop 2014;8:3-10.

[4] Shorter D, Hong T, Osborn DA. Cochrane Review: Screening programmes for developmental dysplasia of the hip in newborn infants. Evid Based Child Health 2013;8:11-54.

[5] Orak MM, Onay T, Cagirmaz T, Elibol C, Elibol FD, Centel T. The reliability of ultrasonography in developmental dysplasia of the hip: How reliable is it in different hands? Indian J Orthop 2015;49:610-4.

[6] Mahan ST, Katz JN, Kim YJ. To screen or not to screen? A decision analysis of the utility of screening for developmental dysplasia of the hip. J Bone Joint Surg Am 2009;91:1705-19.

[7] Schwend RM, Schoenecker P, Richards BS, Flynn JM, Vitale M, Pediatric Orthopaedic Society of North A. Screening the newborn for developmental dysplasia of the hip: now what do we do? J Pediatr Orthop 2007;27:607-10.

[8] Sewell MD, Eastwood DM. Screening and treatment in developmental dysplasia of the hip-where do we go from here? Int Orthop 2011;35:1359-67.

[9] Roposch A, Moreau NM, Uleryk E, Doria AS. Developmental dysplasia of the hip: quality of reporting of diagnostic accuracy for US. Radiology 2006;241:854-60.

[10] Ortiz-Neira CL, Paolucci EO, Donnon T. A meta-analysis of common risk factors associated with the diagnosis of developmental dysplasia of the hip in newborns. Eur J Radiol 2012;81:e344-51.

[11] Garvey M, Donoghue VB, Gorman WA, O'Brien N, Murphy JF. Radiographic screening at four months of infants at risk for congenital hip dislocation. J Bone Joint Surg Br 1992;74:704-7. [12] Tafazal S, Flowers MJ. Do we need to follow up an early normal ultrasound with a later plain radiograph in children with a family history of developmental dysplasia of the hip? Eur $\mathrm{J}$ Orthop Surg Traumatol 2015;25:1171-5.

[13] Keller MS, Nijs EL. The role of radiographs and US in developmental dysplasia of the hip: how good are they? Pediatr Radiol 2009;39 Suppl 2:S211-5.

[14] Holen KJ, Tegnander A, Bredland T, Johansen OJ, Saether OD, Eik-Nes SH, et al. Universal or selective screening of the neonatal hip using ultrasound? A prospective, randomised trial of 15,529 newborn infants. J Bone Joint Surg Br 2002;84:88690.

[15] Bache CE, Clegg J, Herron M. Risk factors for developmental dysplasia of the hip: ultrasonographic findings in the neonatal period. J Pediatr Orthop B 2002;11:212-8.

[16] Arumilli BR, Koneru P, Garg NK, Davies R, Saville S, Sampath J, et al. Is secondary radiological follow-up of infants with a family history of developmental dysplasia of the hip necessary? J Bone Joint Surg Br 2006;88:1224-7.

[17] Price KR, Dove R, Hunter JB. The use of X-ray at 5 months in a selective screening programme for developmental dysplasia of the hip. J Child Orthop 2011;5:195-200.

[18] Osarumwense D, Popple D, Kershaw IF, Kershaw CJ, Furlong AJ. What follow-up is required for children with a family history of developmental dysplasia of the hip? J Pediatr Orthop B 2007; 16:399-402.

[19] Lee YK, Chung CY, Koo KH, Lee KM, Kwon DG, Park MS. Measuring acetabular dysplasia in plain radiographs. Arch Orthop Trauma Surg 2011;131:1219-26. 